UCID--19339

DE82 013922

\title{
STRESS-POINT ALGORITHM FOR A PRESSURE-SENSITIVE MULTIPLE-YIELD-SURFACE PLASTICITY THEORY
}

\author{
Thomas J.R. Hughes \\ 903 Cottrell Way \\ Stanford, California 94305
}

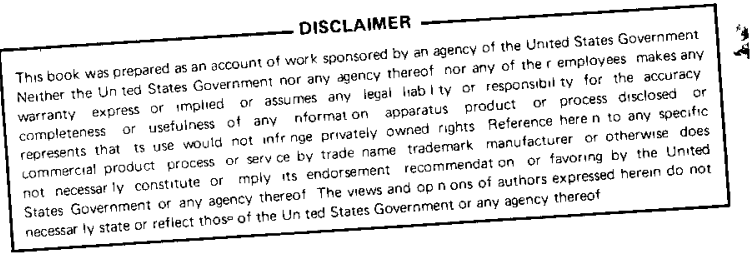

March, 1982

$-\mathrm{i} i-$ 


\section{DISCLAIMER}

This report was prepared as an account of work sponsored by an agency of the United States Government. Neither the United States Government nor any agency Thereof, nor any of their employees, makes any warranty, express or implied, or assumes any legal liability or responsibility for the accuracy, completeness, or usefulness of any information, apparatus, product, or process disclosed, or represents that its use would not infringe privately owned rights. Reference herein to any specific commercial product, process, or service by trade name, trademark, manufacturer, or otherwise does not necessarily constitute or imply its endorsement, recommendation, or favoring by the United States Government or any agency thereof. The views and opinions of authors expressed herein do not necessarily state or reflect those of the United States Government or any agency thereof. 


\section{DISCLAIMER}

Portions of this document may be illegible in electronic image products. Images are produced from the best available original document. 


\section{CONTENTS}

Page

ABSTRACT . . . . . . . . . . . . . . . . . . . . . . 1

1. INTRODUCTION . . . . . . . . . . . . . . . . . . 1

2. THEORY . . . . . . . . . . . . . . . . . . . 3

3. ALGORITHM ....................... . . 11

4. SUBINCREMENTAL STRATEGY FOR REDUCING THE "DISCREPANCY:" CF. (32). 16

5. SOFTWARE . . . . . . . . . . . . . . . 18

6. NUMERICAL RESULTS . . . . . . . . . . . . . . . . 19

7. CONCLUSIONS . . . . . . . . . . . . . . . . . 38

REFERENCES . . . . . . . . . . . . . . . . . . . . 39 


\title{
STRESS-POINT ALGORITHM FOR A PRESSURE-SENSITIVE MULTIPLE-YIELD-SURFACE PLASTICITY THEORY
}

\begin{abstract}
A pressure-sensitive multiple-yield-surface plasticity theory is presented for application to the multi-dimensional cyclic response of soil media. A stress-point numerical algorithm is developed as the basis of a computer module designed to interface with large-scale finite element computer programs used at LLNL.
\end{abstract}

\section{INTRODUCTION}

In recent years, it has been shown in a number of papers that multipleyield-surface plasticity theories have significant potential in accurately characterizing the behavior of a variety of soil media subjected to cyclic inputs. The original concept of multiple yield surfaces apparently is due to Mroz [7], was further developed by Iwan [3], and extensively applied to soils by Prévost [9-13] and others (e.g., [8]). Theories of this type are significantly more complicated than the classical plasticity theories now widely used in engineering analysis. From a continuum mechanics standpoint, the predictive behavior of multiple-yield-surface theories is not yet fully understood, especially with regard to pressure-sensitive phenomena of importance in soil response. Furthermore, due to the complexity of these theories, initial numerical implementations have not been as efficient and reliable as is possible. Application of constitutive models of this type to large-scale problem solving has thus been limited to some extent.

Reported upon here is the development of a pressure-sensitive multipleyield-surface plasticity theory which is a variation of the one presented by Prévost [12]. The hardening rules employed allow for an arbitrary linear combination of isotropic and kinematic hardening in the manner described by 
Krieg and Key [5]. An effort has been made in Section 2 to present the theory in a clear way so that it may be understood by someone with a background in the classical plasticity theories.

In Section 3 an incremental version of the theory is presented for purposes of developing a numerical algorithm. The approach is believed to be novel in that it makes heavy use of the "radial return" ideas of implementation, discussed by Krieg and Key [5] and Krieg and Krieg [6]. This enables the numerical algorithm to perform reliably and accurately at much larger step sizes than would otherwise be possible with more straightforward and traditional implementations, and thus opens the way to application in large-scale problem-solving environments.

Numerical results and conclusions are presented in Sections 4 and 5, respectively. 


\section{THEORY}

The main equations of the theory are given as follows:

$$
\begin{aligned}
& \dot{\sigma}=\underset{\sim}{c} \cdot\left(\dot{\sim}_{\tilde{\varepsilon}}-\dot{\sim}^{p l}\right) \quad \text { constitutive equation } \\
& \dot{\mathrm{k}}=a \dot{\varepsilon}^{p l} \quad \text { isotropic hardening rule } \\
& \dot{\alpha}=b|\underset{\sim}{P}| \lambda \underset{\sim}{\mu} \quad \text { kinematic hardening rule } \\
& \stackrel{\sim}{\varepsilon}^{p l}=\lambda \underset{\sim}{P} \quad \text { flow rule } \\
& f(\underset{\sim}{)})=\frac{3}{2}\left|\xi^{\prime}\right|^{2}+c^{2}\left|\xi^{\prime \prime}\right|^{2}=3 k^{2} \quad \text { yield function }
\end{aligned}
$$

where

$$
\begin{aligned}
& \underset{\sim}{\sigma} \quad=\quad \text { Cauchy stress tensor } \\
& \text { C = isotropic elastic coefficients matrix } \\
& \varepsilon \quad=\quad \text { ("small") strain tensor } \\
& {\underset{\sim}{p l}}^{p l}=\text { plastic strains tensor } \\
& \mathrm{k}=\mathrm{yield} \text { surface size parameter } \\
& \dot{\varepsilon}^{p l}=\sqrt{\frac{2}{3}}\left|{\underset{\sim}{e}}^{\dot{e} l}\right| ;\left|{\underset{\sim}{p l}}^{p l}\right|=\left(\dot{\varepsilon}_{i j}^{p l} \dot{\varepsilon}_{i j}^{p l}\right)^{1 / 2} \text {, etc. } \\
& \alpha=\text { center of yield surface in stress space } \\
& \underset{\sim}{\mu} \quad=\quad \text { direction of instantaneous translation of yield surface center } \\
& \stackrel{\mathrm{P}}{\sim} \quad=\text { direction of instantaneous plastic straining } \\
& \mathrm{a}, \mathrm{b}, \lambda=\text { hardening parameters } \\
& \xi \quad=\quad \sigma-\alpha
\end{aligned}
$$




$$
\begin{aligned}
& {\underset{\sim}{\xi^{\prime}}}^{\prime}=\underset{\sim}{\xi}-\xi^{\prime \prime} \underset{\sim}{I}, \text { deviatoric part of } \underset{\sim}{\xi} \\
& \xi^{\prime \prime}=\frac{1}{3} \operatorname{tr} \underset{\sim}{\xi}, \text { dilatational part of } \underset{\sim}{\xi} \\
& I \quad \text { identity } \\
& c \quad=\text { axis ratio }
\end{aligned}
$$

and a superposed dot denotes time differentiation and repeated indices are assumed summed. 


\section{Remarks}

1. From (5) it may be seen that the yield surfaces are ellipsoids in $\xi^{\prime \prime},\left|\xi^{\prime}\right|$-space. Restricted to the deviatoric plane, they are circular. See Fig. 1. The radius in the deviatoric plane is given by $R=\sqrt{2} \mathrm{k}$.

2. The axis ratio, $c$, is the same for all yield surfaces. In the limit $c \rightarrow 0$, the yield surfaces become Mises cylinders (see Fig. 2).

3. There may be any number of yield surfaces. The direction vector, $\underset{\sim}{\mu}$, of the outermost surface is taken parallel to the normal. For the inner surfaces, $\underset{\sim}{\mu}$ points in the direction of the "conjugate point" of the next larger yield surface. Conjugate points have parallel outward normals with the same orientation. See Fig. 3. In this way, no overlap of surfaces is possible. Luring plastic loading, the outermost surface engaged by the stress point is considered active and the inner surfaces remain attached to this point throughout its motion. During elastic unloading, the stress point moves within the innermost surface, which is stationary, until it impinges upon it, at which point plastic loading again may begin. The yield surfaces, in general, may translate and change size, but never ratate. Further details concerning the motion of the yield surfaces may be found in Refs. 9-13.

For the materials of interest to us, it suffices to take $P$ to be of the following form:

$$
\left.\begin{array}{l}
\underset{\sim}{P}=\underset{\sim}{P^{\prime}}+P^{\prime \prime} \underset{\sim}{I} \\
P_{\sim}^{\prime}=\underset{\sim}{Q^{\prime}} \\
\left.P^{\prime \prime}=Q^{\prime \prime}+A \operatorname{tr}\left({\underset{\sim}{Q}}^{\prime}\right)^{3}\right) / \operatorname{tr}\left({\left.\left.\underset{\sim}{Q^{\prime}}\right)^{2}\right)}^{\underline{Q}}=\operatorname{grad} f / 1 \operatorname{grad} f \mid\right. \\
\operatorname{grad} f=3 \underset{\sim}{\xi}+\left(\frac{2}{9} c^{2}-1\right) \operatorname{tr} \underset{\sim}{\underset{\sim}{I}}
\end{array}\right\}
$$




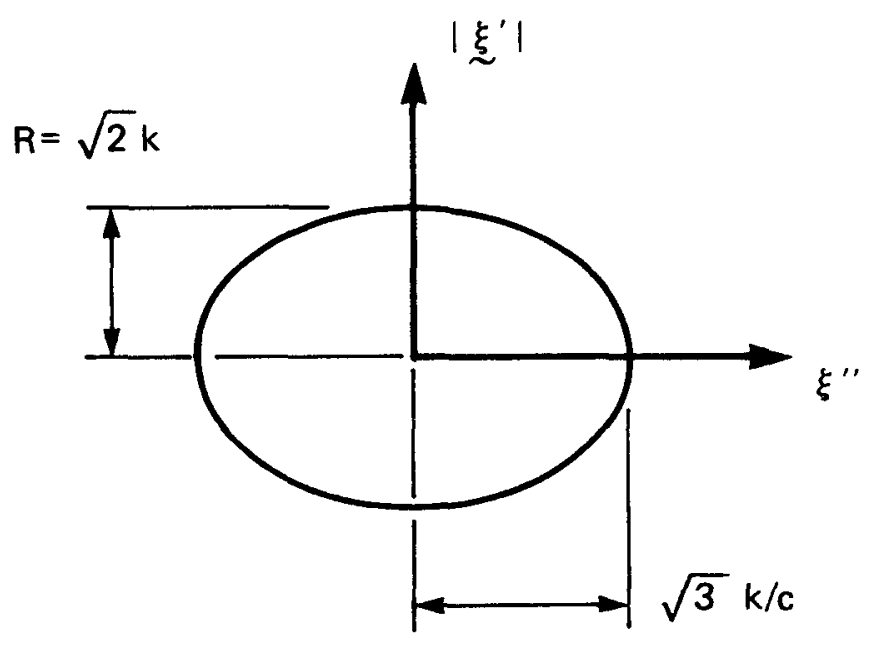

FIG. 1. Yield surface in $\xi ",|\underline{\mid \xi}|$ - space.

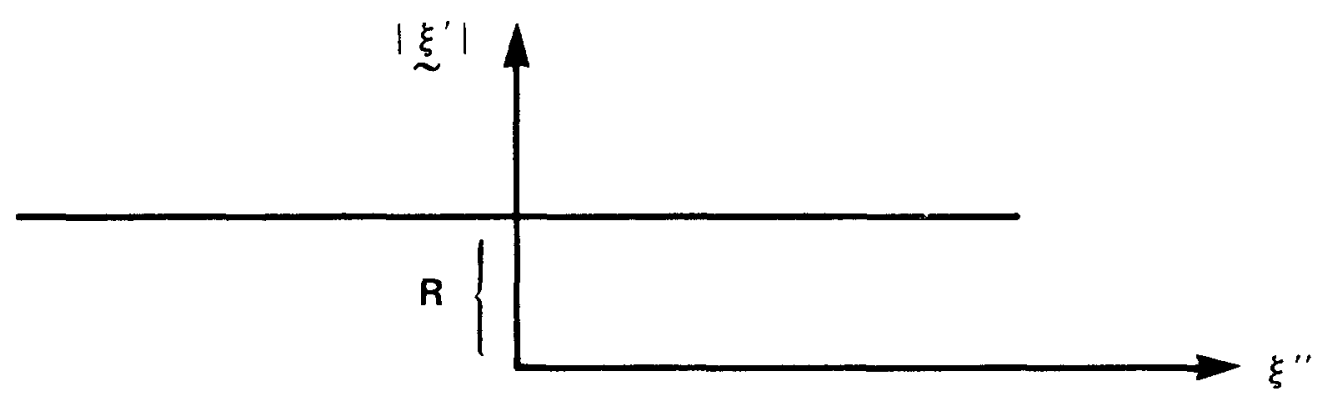

FIG. 2. Mises cylinders in limit $c \rightarrow 0$. 
where $A$ is a given measure of the "non-associativity" of the flow rule. Observe that $\underset{\sim}{Q}$ defines the outward normal to the yield surface. The form of $\underset{\sim}{\mathcal{P}}$ may be taken to be different without essential alteration to the subsequent developments. Note that the non-associativity is restricted to the $\xi^{\prime \prime},\left|\xi^{\prime}\right|-$-plane. See Fig. 4.

A plasticity matrix, $\stackrel{\sim}{\sim}^{p l}$, is introduced and required to satisfy

$$
\tilde{\sim}^{p l} \cdot \underset{\sim}{\dot{\varepsilon}}=\underset{\sim}{c} \cdot \stackrel{\sim}{\dot{\varepsilon}}^{p l}
$$

The precise form of ${\underset{\sim}{p l}}^{p l}$ is given by

$$
\underset{\sim}{C^{p l}}=\frac{1}{H^{\prime}+H_{0}}(\underset{\sim}{C} \cdot \underset{\sim}{P})(\underset{\sim}{Q} \cdot \underset{\sim}{C})
$$

where

$H_{0}=\underset{\sim}{Q} \cdot \underset{\sim}{C} \cdot \underset{\sim}{P}=Q_{i j} C_{i j k \ell} P_{k \ell}=B \operatorname{tr} \underset{\sim}{P} \operatorname{tr} \underset{\sim}{Q}+2 G \underset{\sim}{P^{\prime}} \cdot \stackrel{\sim}{Q}^{\prime}$

$H^{\prime}=h^{\prime}+\frac{\operatorname{tr} \underset{\sim}{Q}}{\sqrt{3}} B^{\prime}$

in which $B$ and $G$ are the elastic bulk and shear moduli, respectively, and $h$ ' and $B^{\prime}$ are plastic moduli associated with each yield surface. From (13) it may be concluded that $h$ ' plays the role of a shearing modulus and $h ' \pm B$ ' plays the role of a consolidation modulus. See Fig. 5.

The meaning of (11) is perhaps more clearly perceived if written in indicial notation:

$$
c_{i j k \ell}^{p \ell}=\frac{1}{H^{\prime}+H_{0}} C_{i j m n} P_{m n} Q_{p q} C_{p q k \ell}
$$

Combining (4), (10), and (11) enables us to obtain an expression for $\lambda$ :

$$
\lambda=\underset{\sim}{Q} \cdot \underset{\sim}{C} \cdot \underset{\sim}{\dot{\varepsilon}} /\left(H^{\prime}+H_{0}\right)
$$




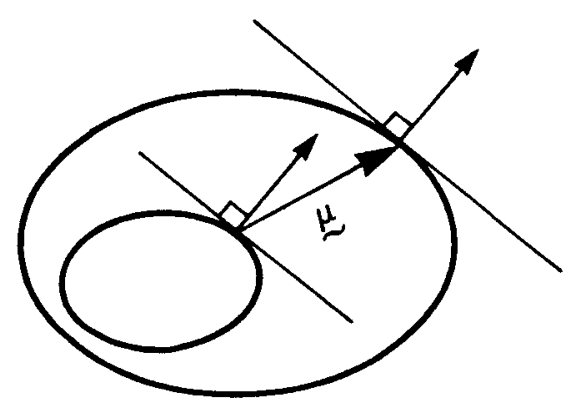

FIG. 3. Direction vector $\underline{\sim}$.

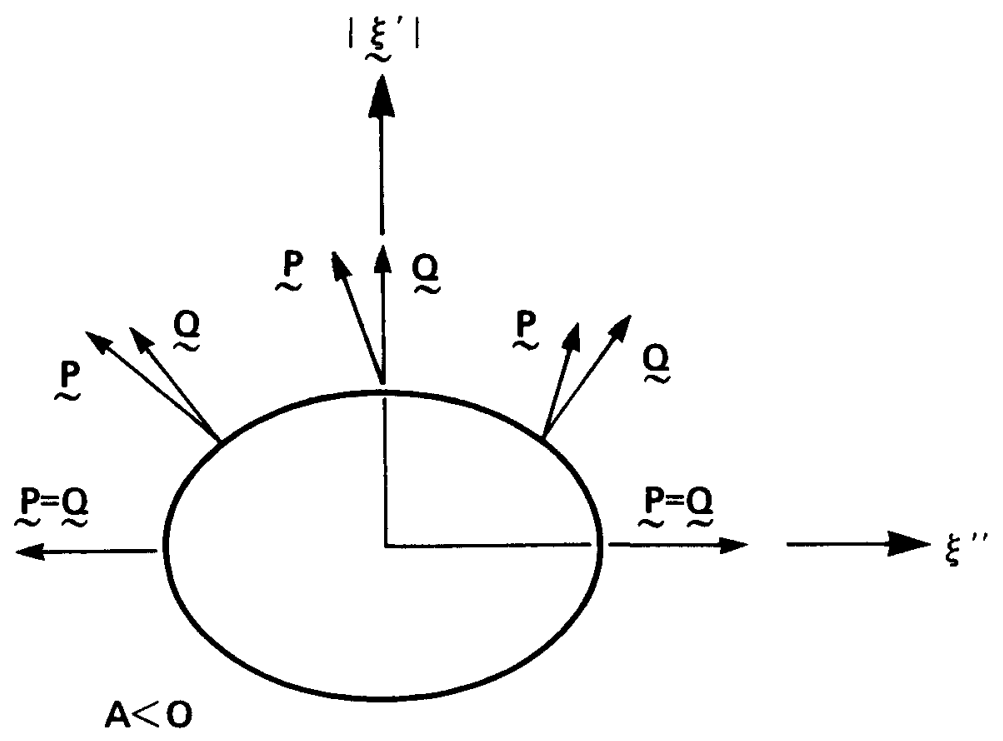

FIG. 4. Direction of plastic strain and normal. 
Another expression for $\lambda$ is obtained from the consistency condition which emanates from time differentiating (5):

$$
\dot{f}(\underset{\sim}{\xi})=\underset{\sim}{Q} \cdot \underset{\sim}{\dot{\xi}}=6 \mathrm{k} \dot{k}
$$

Employing (1) - (4) in (16) yields

$\lambda=\underset{\sim}{Q} \cdot \underset{\sim}{C} \cdot \underset{\sim}{\varepsilon /[Q} \underset{\sim}{Q} \cdot(\underset{\sim}{C} \cdot \underset{\sim}{P}+b|\underset{\sim}{P}| \underset{\sim}{\mu})+2 \sqrt{6} a|\underset{\sim}{P}| k]$

Combining (15) and (17) places a constraint on a and b. For example, let us assume $a=0$. (In this case, the sizes of the yield surfaces remain constant.) Then $b$ takes on the form

$$
b=H^{\prime} /(|\underset{\sim}{P}| \underset{\sim}{Q} \cdot \underset{\sim}{\mu})
$$

To allow for an arbitrary linear combination of isotropic and kinematic hardening, define $b$ as follows:

$$
b=(1-\beta) H^{1} /(|\underset{\sim}{P}| \underset{\sim}{Q} \cdot \underset{\sim}{\mu})
$$

where $\beta$ is a parameter. Equations (15), (17), and (19) then serve to define a:

$$
a=\beta H^{\prime} /(2 \sqrt{6}|\underset{\sim}{P}| k)
$$

As may be seen from (19) and (20), $\beta=0$ corresponds to kinematic hardening and $\beta=1$ to isotropic hardening. Substituting (19) and (20) into (2) and (3), respectively, leads to

$$
\begin{aligned}
& \dot{k}=\lambda \beta H^{\prime} /(6 k) \\
& \dot{\alpha}=\lambda(1-\beta) H^{\prime} \underset{\sim}{\mu}(\underset{\sim}{Q} \cdot \underset{\sim}{\mu})
\end{aligned}
$$

Observe that one value of $\beta$ pertains to all yield surfaces. 


\section{Remarks}

1. The preceding formulation has been described within the context of small-deformation theory for simplicity. The generalization to the large deformation case may be facilitated by replacing the material time derivative by an objective rate and by replacing the strain rate with the rate-of-deformation tensor (i.e. the symmetrical part of the spatial velocity gradients, see e.g. Ref. 5). 


\section{ALGORITHM}

The approximate incremental versions of (1), (21) and (22) are, respectively:

$$
\begin{aligned}
& \underset{\sim}{\sigma}{ }_{n+1}=\underset{\sim}{t r} \sigma_{n+1}^{t r}-\underset{\sim}{p l} \\
& k_{n+1}=k_{n}+\tilde{\lambda} \beta H^{\prime} /(6 k) \\
& \left.\underset{\sim}{\alpha} n+1=\underset{\sim}{\alpha}+\tilde{\lambda}(1-\beta) H^{\prime} \underset{\sim}{\mu} \underset{\sim}{Q} \cdot \underset{\sim}{\mu}\right)
\end{aligned}
$$

where

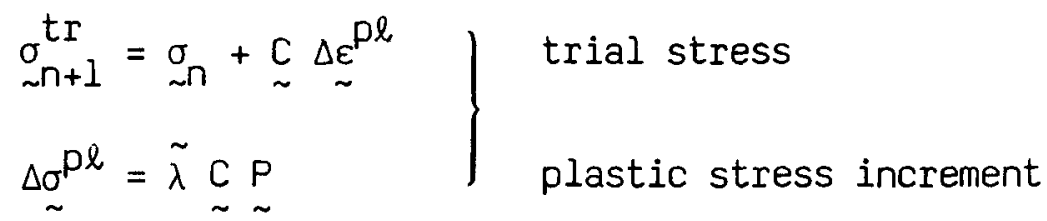

in which $\underset{\sim}{\Delta l}$ is the plastic strain increment, and a subscript denotes the step number.

The parameter $\tilde{\lambda}$ is determined by an incremental version of the consistency condition. To this end we define

$$
{\underset{\sim}{n+1}}_{n+1} \operatorname{R}_{n} /|\underset{\sim}{\mid \xi}|_{f}
$$

where $R_{n+1}=\sqrt{2} k_{n+1}, \underset{\sim}{\xi}$ is the vector from $\underset{\sim}{\alpha}$ to the "contact point" on the yield surface, and

$$
|\underset{\sim}{\xi}|_{f}^{2}=\frac{2}{3} f(\underset{\sim}{\xi})
$$

The contact point on the yield surface at step $n$ is the point at which $\stackrel{g}{n+1}_{n}^{\operatorname{tr}}-a_{n}$ intersects the yield surface. See Fig. 6. Note that the value of $\xi_{n+1}$ given by (28) is not necessarily the same as that given by (23) and (25) (i.e. ${\underset{\sim}{n+1}}_{n}-{\underset{\sim}{n+1}}_{n+1}$ ). It may be verified that (28) satisfies the yield function. That is, the tip of ${\underset{\sim}{n+1}}_{n}$ lies on the yield surface.

The incremental version of consistency is 


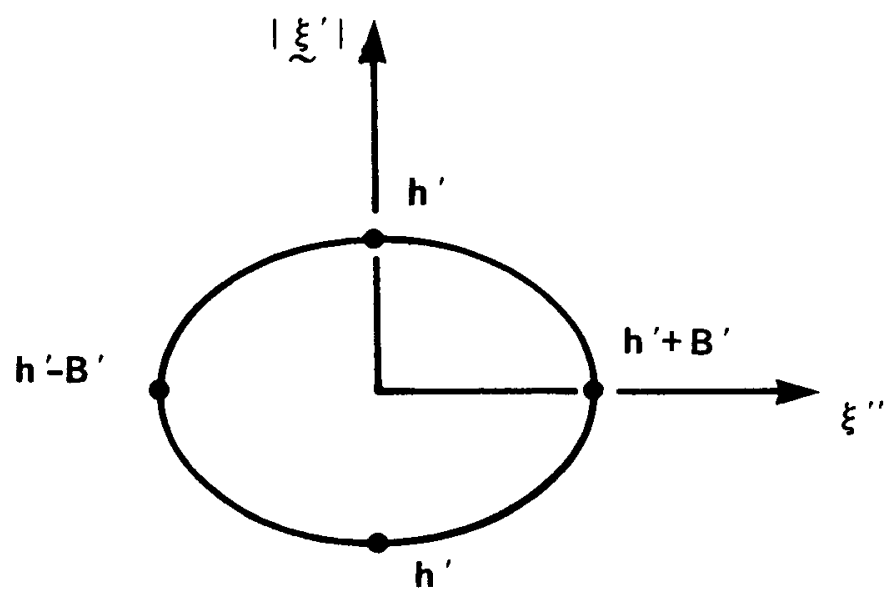

FIG. 5. Plastic modulus, $H^{\prime}$, at various positions on yield surface.

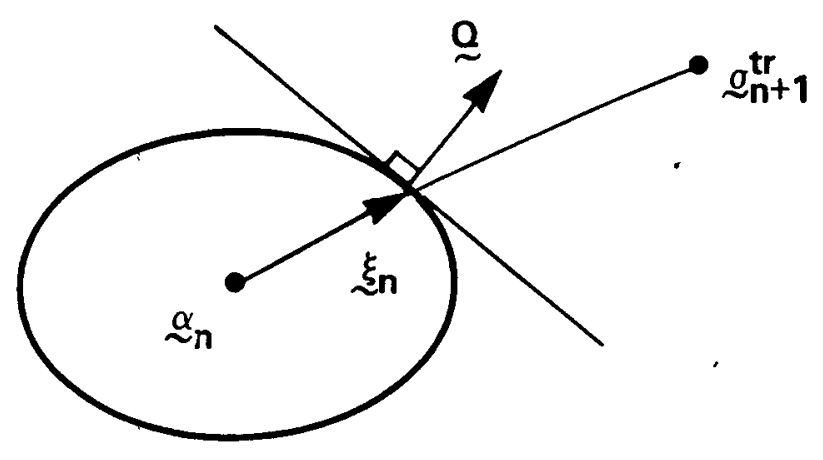

FIG. 6. Contact point on yield surface. 


$$
\stackrel{Q}{\sim} \cdot\left(\sigma_{n+1}-\alpha_{\sim n+1}^{\alpha}-{\underset{\sim}{n+1}}_{n+1}\right)=0
$$

Substituting (23) - (25), (27) and (28) into (30) leads to the following expression for $\tilde{\lambda}$ :

$$
\tilde{\lambda}=\left(\underset{\sim}{\sigma_{n+1}}-{\underset{\sim}{\alpha}}_{n}-\underset{\sim}{\xi}\right) \cdot \underset{\sim}{Q} /\left(H^{\prime}+H_{0}\right)
$$

When this value is substituted into (23) - (25), (27) and (28), the "discrepancy,"

$$
\underset{\sim}{\sigma}+1-\underset{\sim n+1}{\alpha}-\xi_{n+1}
$$

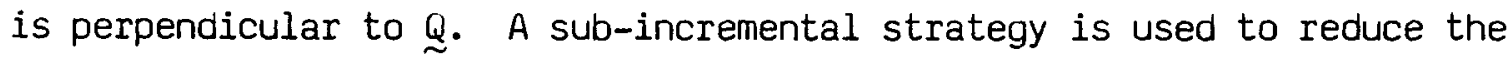
discrepancy to zero. This will be described subsequently.

It may occur that, after completion of the preceding calculations, it is found that the stress point lies outside the next larger yield surface. When this is the case the value of $g_{n+1}^{t r}$ is reinitialized to $g_{n+1}$ and $k_{n}$ and $\underset{\sim}{\alpha}$ are replaced by $k_{n+1}$ and ${\underset{n}{n+1}}_{1}$, respectively. Calculations at this point begin again with respect to the next yield surface. However, some small, but crucial, modifications must be made to take account of the fact that $g_{n+1}^{t r}$ is no longer an "elastic" trial stress.

To see the origin of the necessary changes, assume that loading was just performed with respect to yield surface $m-1$ and that it is now discovered that the resulting stress point is outside surface $m$. In this case, the matrix $\underset{\sim}{ }$ in (27) must be replaced by the elastic-plastic matrix associated with surface $\mathrm{m}-1$, viz.

$$
\underset{\sim}{C}-\frac{1}{H_{m-1}^{\prime}+H_{0}}(\underset{\sim}{\sim})(\underset{\sim}{\sim} \underset{\sim}{C})
$$

in which case

$$
\Delta \sigma^{p l}=\frac{1}{1+H_{0} / H_{m-1}^{\prime}} \tilde{\lambda} \underset{\sim}{\mathrm{P}}
$$

Note that (27) and (34) only differ by a scalar factor of proportionality. 
The plastic modulus, $\mathrm{H}^{\prime}{ }_{\mathrm{m}}$, is a parameter defined with reference to the elastic modulus, $H_{0}$. An elastic-plastic, or tangent, modulus may be defined by

$$
H_{m}=\left(1 / H_{0}+1 / H^{\prime}\right)^{-1}
$$

Formally defining $\mathrm{H}_{0}{ }_{0}=0$, makes (35) consistent with the elastic case. It is necessary to employ a plastic modulus, in place of $\mathrm{H}^{\prime}{ }_{\mathrm{m}}$, defined with reference to the tangent modulus of the previous surface, namely $H_{m-1}$. Physically speaking, this madulus is $H_{m-1}$ times the ratio of increment of position and size of the yield surface to plastic stress increment. The desired quantity is

$$
H_{m} /\left(1-H_{m} / H_{m-1}\right)
$$

Fig. 7 is helpful in understanding the meaning of (36). (36) need be employed in place of $H^{\prime} \mathrm{m}$ in (24) and (25). If, in addition, (34) is used in place of (27), then $\tilde{\lambda}$ becomes

$$
\tilde{\lambda}=(\underset{\sim n+1}{\operatorname{tr}}-\underset{\sim n}{\alpha}-\underset{\sim}{\xi}) \cdot \underset{\sim}{Q} /\left(H_{m} /\left(1-H_{m} / H_{m-1}\right)+H_{m-1}\right)
$$

Note that only the denominator has changed (cf. (31)).

It should be apparent from the previous developments that calculations for subsequent yield surfaces within a step are essentially the same as for the surface first loaded within the step. This simplifies the coding considerably. 


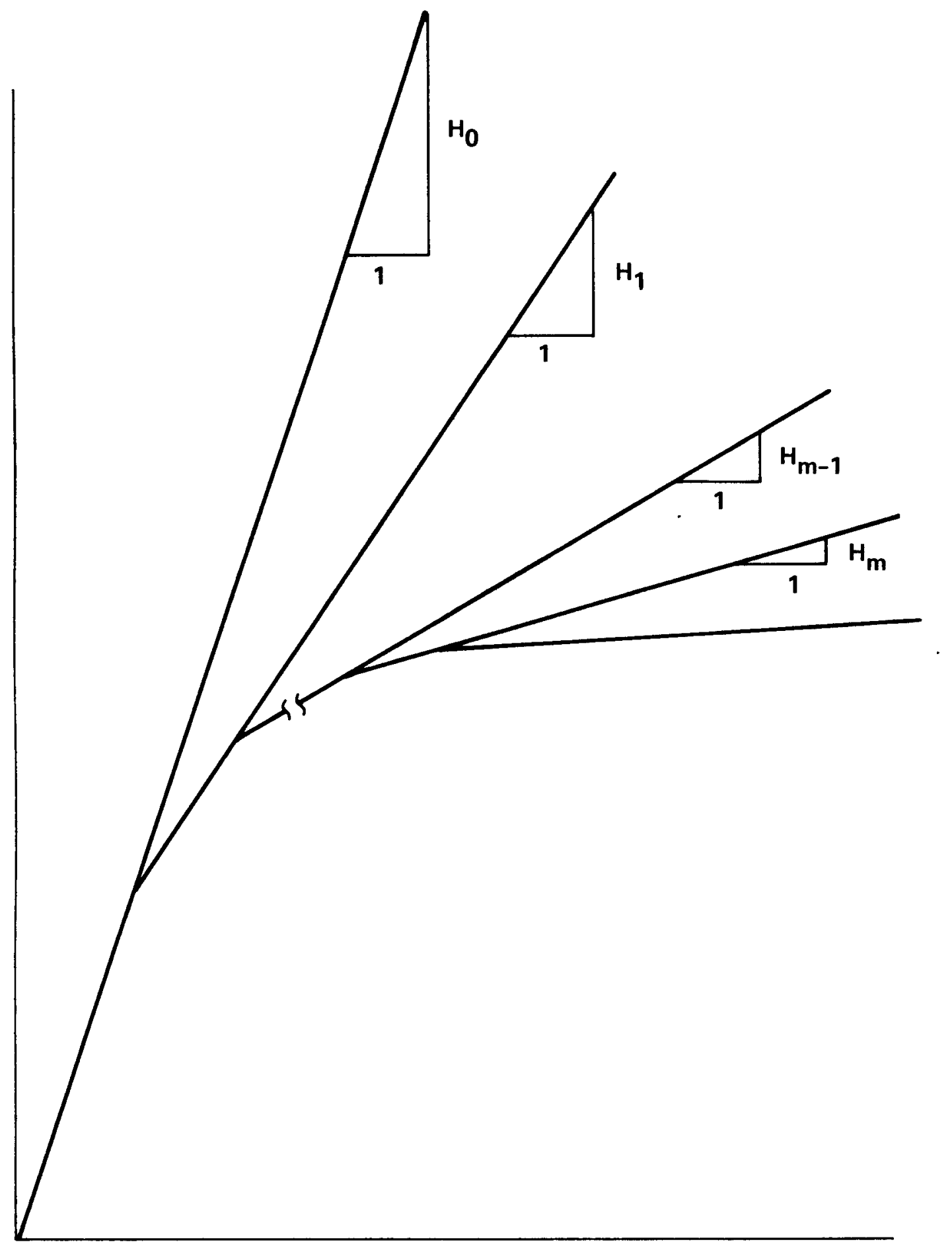

FIG. 7. Schematic of elastic-plastic moduli.

$-15-$ 


\section{SUBINCREMENTAL STRAGEGY FOR REDUCING THE “DISCREPANCY:” (32)}

If the value of the discrepancy is too large, only a fraction of $\tilde{\lambda}$ is applied and the incremental calculations are repeated starting with the latest values of $q_{n+1}, k_{n+1}$ and $a_{n+1}$ in place of $q_{n+1}^{t r}, k_{n}$ and $q_{n}$, respectively. Once the discrepancy is reduced to an acceptable level, or the maximum allowable number of subincrements is reached, the final value of $\sigma_{n+1}$ is replaced by its corresponding "contact point" (i.e., it is projected normally onto the yield surface). This is analogous to the radial return process described by Krieg and Key [5].

The fraction of $\tilde{\lambda}$ applied, $\tilde{F} \tilde{\lambda}$, is determined by

$$
F= \begin{cases}1, & e \leq e_{a c c} \\ F_{\text {min }}+e_{a c c}\left(1-F_{m i n}\right) / e, & e>e_{a c c}\end{cases}
$$

where

$$
e=1 \sigma_{n+1}-\alpha_{n+1}-\left.\xi_{n+1}\right|_{f} / R_{n+1}
$$

(The acceptable error, $e_{a c c}$, and minimum fraction, $F_{\min }$ are taken to be 0.1 and 0.5, respectively.) An illustration of (38) is presented in Fig. 8. In the last subincrement the stress point and yield surface approach each other raaially. 


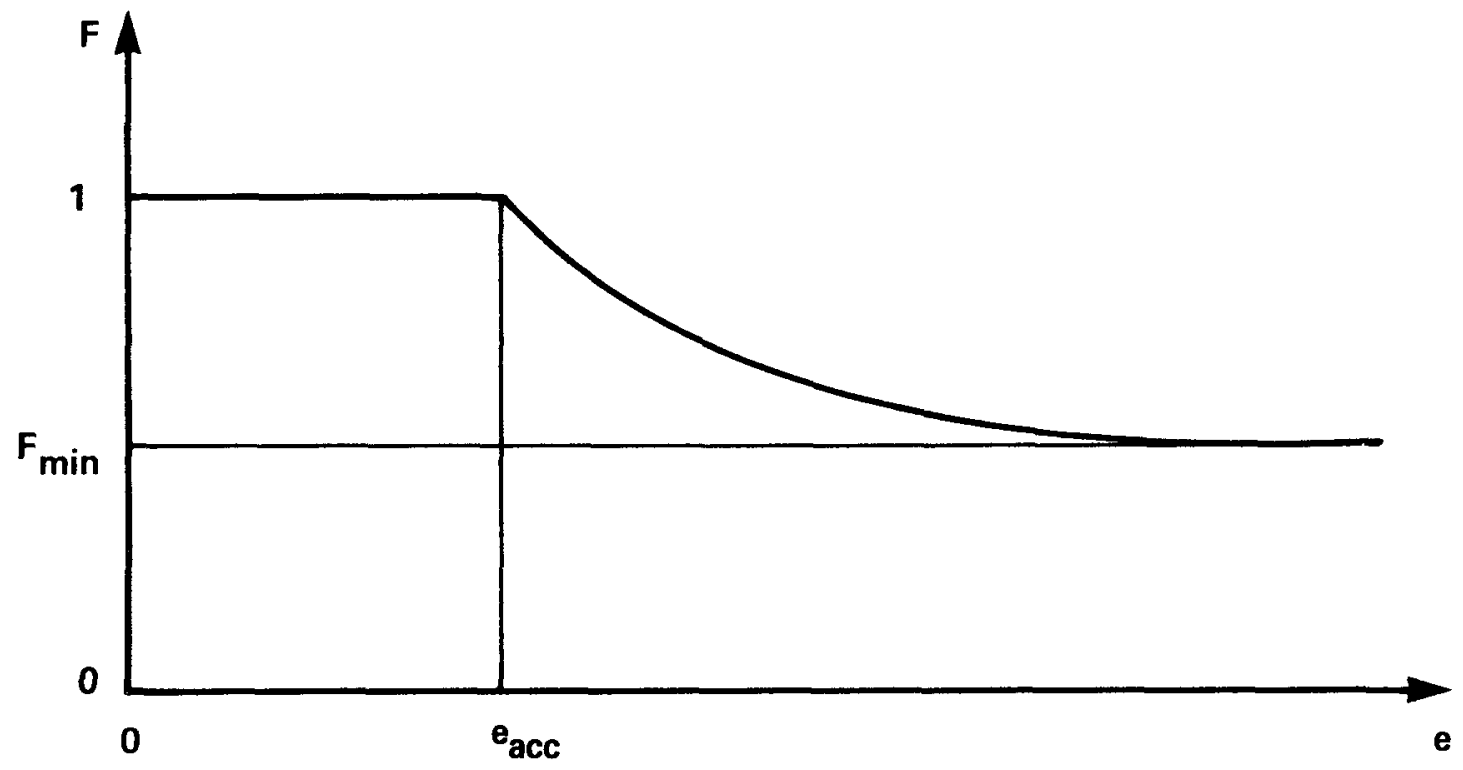

FIG. 8

$-17-$ 


\section{SOFTWARE}

Two software packages have been developed for the type of constitutive theory dealt with herein. These packages have been designed to serve as the constitutive equation modules of large-scale finite element computer programs developed at LLNL. A preliminary pressure-insensitive version of the model has already been implemented in DYNA3D [3], and used successfully to study nonlinear soil effects on site response and soil structure interaction effects on a nuclear power plant $[1,2]$. Efficiency and clarity have been stressed in the implementations.

The most recently developed package, SOILP, manifests all the algorithmic ideas presented in this section. The forerunner to SOILP, called SOILI, was developed in a preliminary study. It is restricted to deviatoric plasticity (i.e., the yield surfaces are Mises cylinders) and it invokes certain other simplifications in the implementation. The main algorithmic simplification is an approximation to the kinematic hardening rule. The direction vector, $\underset{\sim}{\mu}$, is replaced by $\underset{\sim}{\underset{\sim}{W}}$ (i.e., normality), until the stress point on the yield surface impinges upon the next larger yield surface. When this occurs, the inner surface is reoriented to be tangent to the outer (and now active) surface. It may be argued that this represents a discrete approximation to the hardening rule involving $\underset{\sim}{\mu}$. This simplification and those inherent in the deviatoric plasticity case enable SOILI to achieve a greater degree of efficiency than is possible in the fully-general pressure-sensitive case.

A number of deviatoric plasticity test cases have been used to verify SOILl. Unfortunately, very little data is available by which the pressuresensitive behavior of SOILP may be verified. However, it has also been applied to a number of deviatoric test cases which verifies certain aspects of the implementation, and has performed well on the pressure-sensitive cases available. 


\section{NUMERICAL RESULTS}

\section{a. Drammen clay [12]}

The Drammen clay model assumes undrained behavior. Thus only deviatoric plasticity is accounted for in that the yield surfaces are Mises cylinders. The data for the Drammen clay is presented in Table 1. The plastic shear moduli and $\alpha_{i j}$ 's are defined by:

$$
\begin{aligned}
& h^{\prime}=2 h /(2-h / G) \\
& \alpha_{11}=\alpha_{22}=-\alpha_{1} / 3 \\
& \alpha_{22}=2 \alpha_{1} / 3 \\
& \alpha_{i j}=0 \text { if } i \neq j
\end{aligned}
$$

A number of monotonic and cyclic, triaxial and simple shear experiments were run. In triaxial tests, the nonzero input strain component is $\varepsilon_{22}$ ' whereas in simple shear it is $\gamma=2 \varepsilon_{12^{\circ}}$. The nonzero strain component is assumed to take the form:

$\underbrace{\varepsilon_{1}}_{\begin{array}{c}\text { monotonic } \\ \text { component }\end{array}}+\frac{\varepsilon_{\begin{array}{c}\text { cyclic } \\ \text { component }\end{array}}^{\varepsilon_{2} \text { sinwt }}}{\text {. }}$

where

$$
\begin{aligned}
& t=\text { step number/number of steps } \\
& \omega=2 \pi \times \text { number of cycles. }
\end{aligned}
$$

Calculated results are presented in Figs. $9-17$. In the plots of $\sqrt{3} \sigma_{12}$ vs. $\sigma_{22} \sigma_{11}$, the initial positions of the yield surfaces are shown. The results for 1000 steps may be viewed as converged. 
Table 1. Drammen clay data

Elastic properties: $G=200, B=133.33, v=0$ (Poisson's ratio)

Yield surface data: $\beta=0$ (kinematic hardening)

\begin{tabular}{|lllr|}
\hline$m$ & $\alpha_{1}$ & $\sqrt{3} k$ & $h$ \\
\hline 1 & -.100 & 0.300 & 266.667 \\
2 & -.150 & 0.350 & 133.333 \\
3 & -.300 & 0.600 & 100.000 \\
4 & -.400 & 0.700 & 73.333 \\
5 & -.475 & 0.775 & 54.667 \\
6 & -.525 & 0.875 & 40.000 \\
7 & -.550 & 0.950 & 31.000 \\
8 & -.575 & 1.025 & 24.333 \\
9 & -.600 & 1.050 & 17.333 \\
10 & -.575 & 1.125 & 13.333 \\
11 & -.550 & 1.200 & 10.000 \\
12 & -.550 & 1.250 & 6.667 \\
13 & -.525 & 1.275 & 3.333 \\
14 & -.467 & 1.375 & 0.000 \\
\hline
\end{tabular}




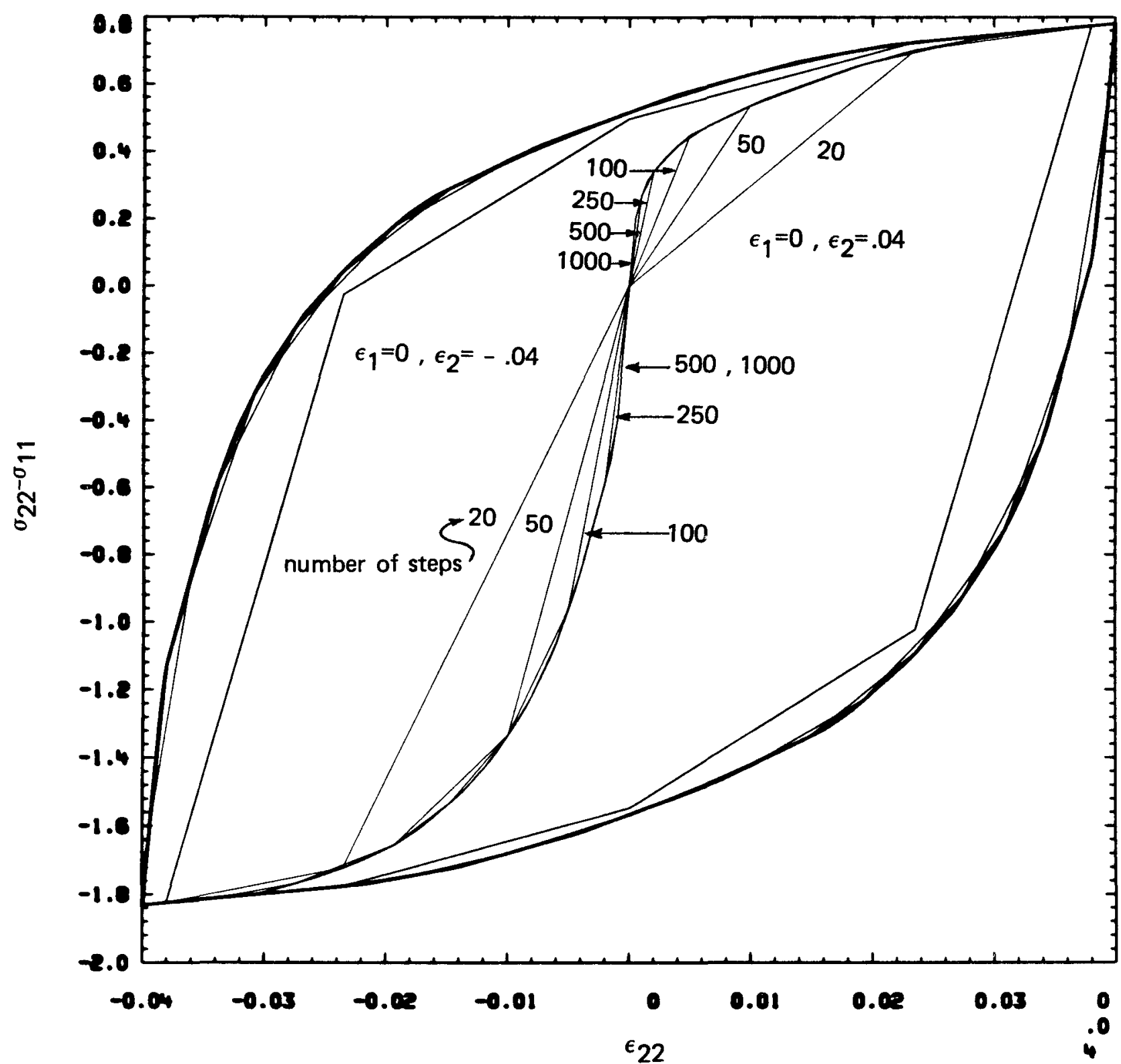

FIG. 9. Drammen clay, triaxial, 2 cycles. 


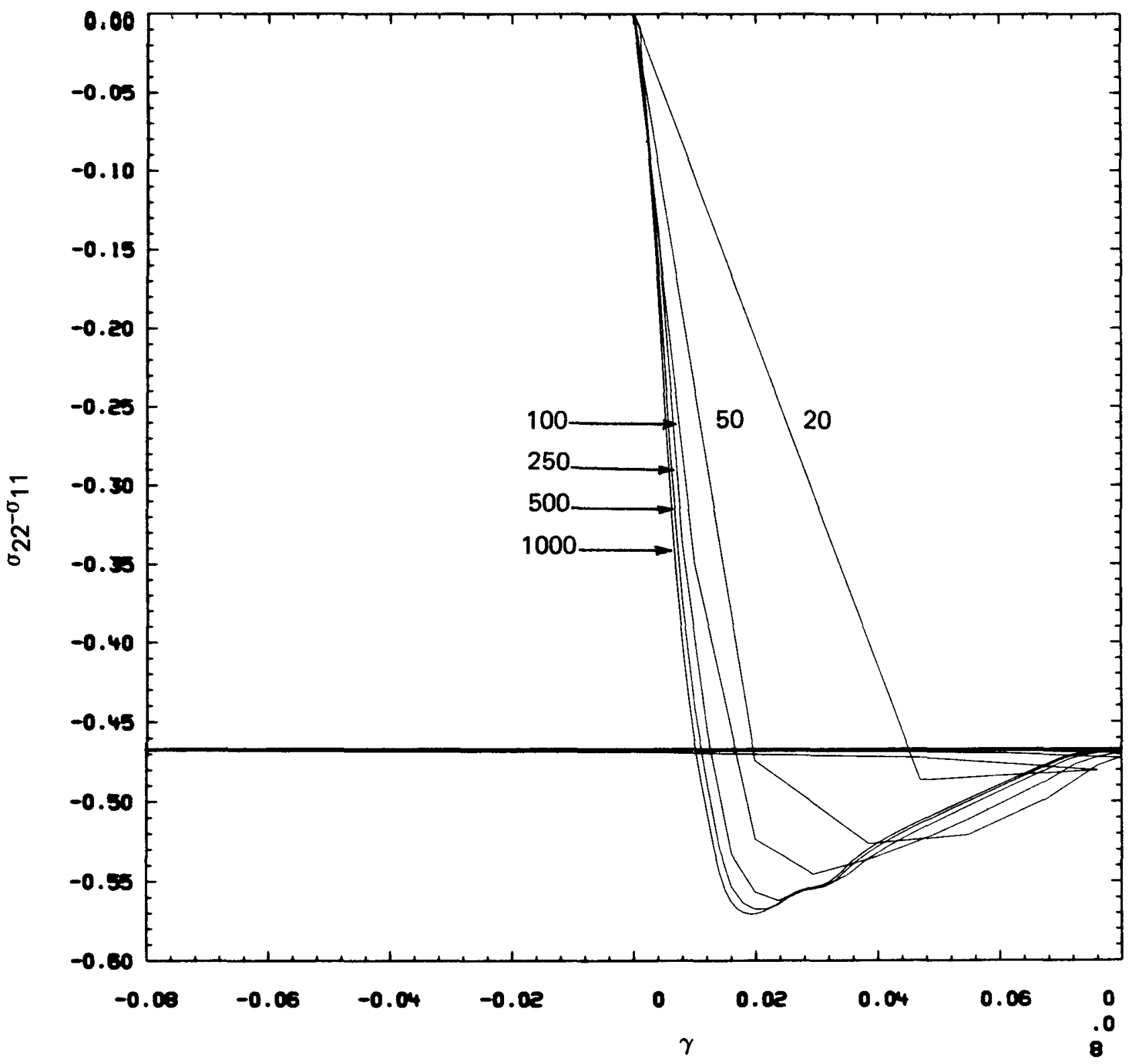

FIG. 10. Drammen clay, simple shear, 2 cycles, $\epsilon_{1}=0, \epsilon_{2}=.08$. 


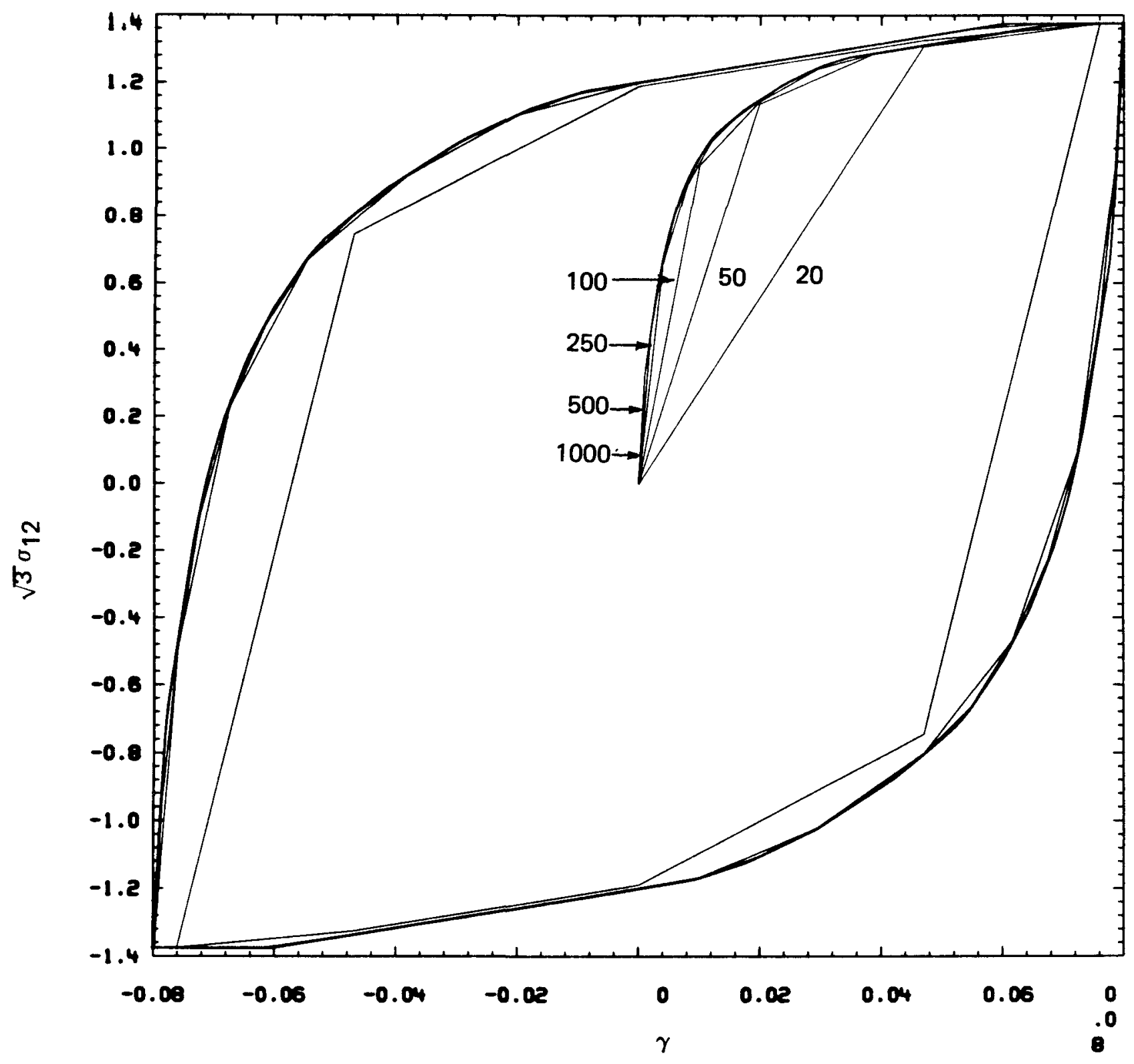

FIG. 11. Drammen clay, simple shear, 2 cycles, $\epsilon_{1}=0, \epsilon_{2}=.08$. 


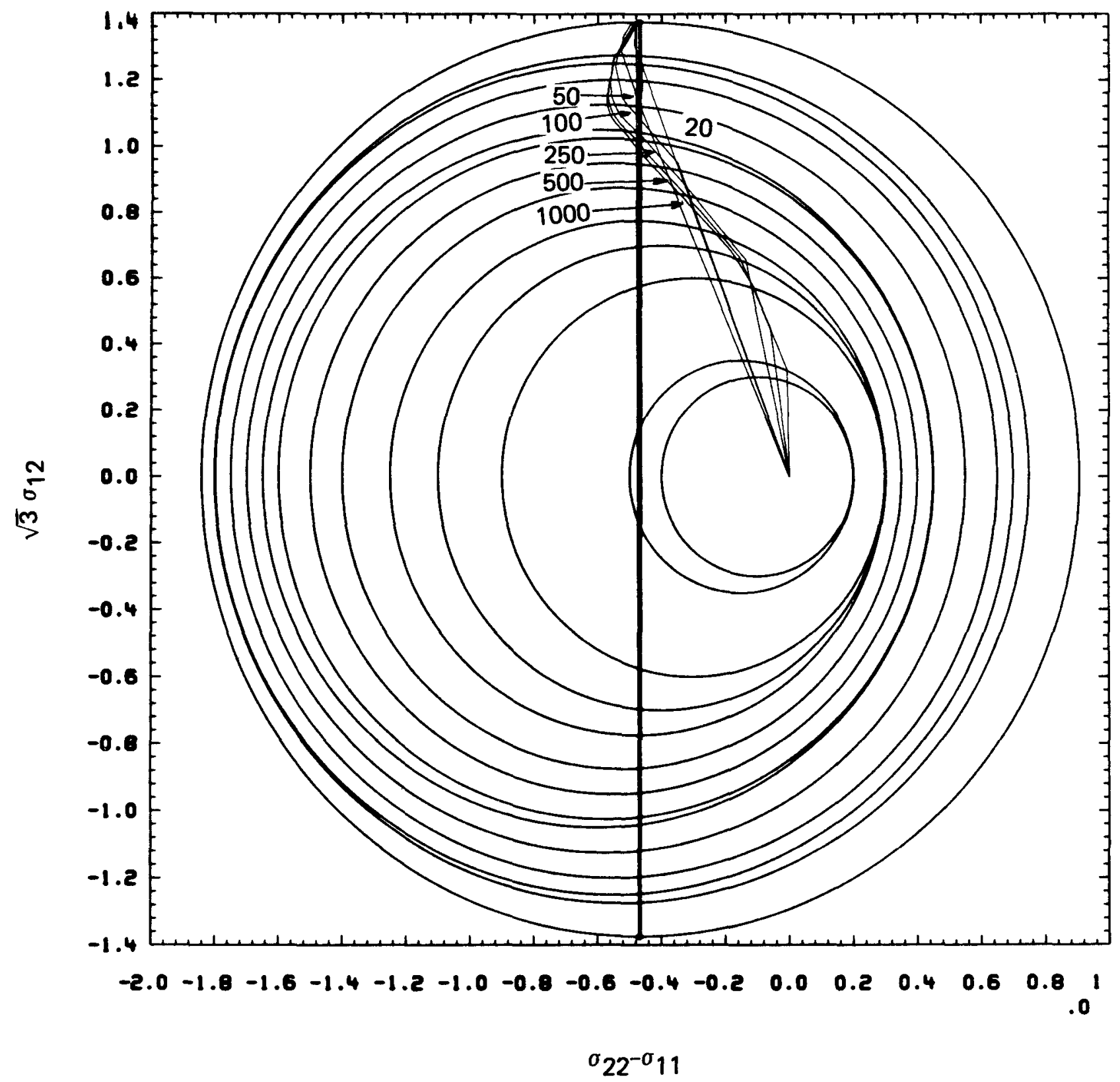

FIG. 12. Drammen clay, simple shear, 2 cycles, $\epsilon_{1}=0, \epsilon_{2}=.08$. 


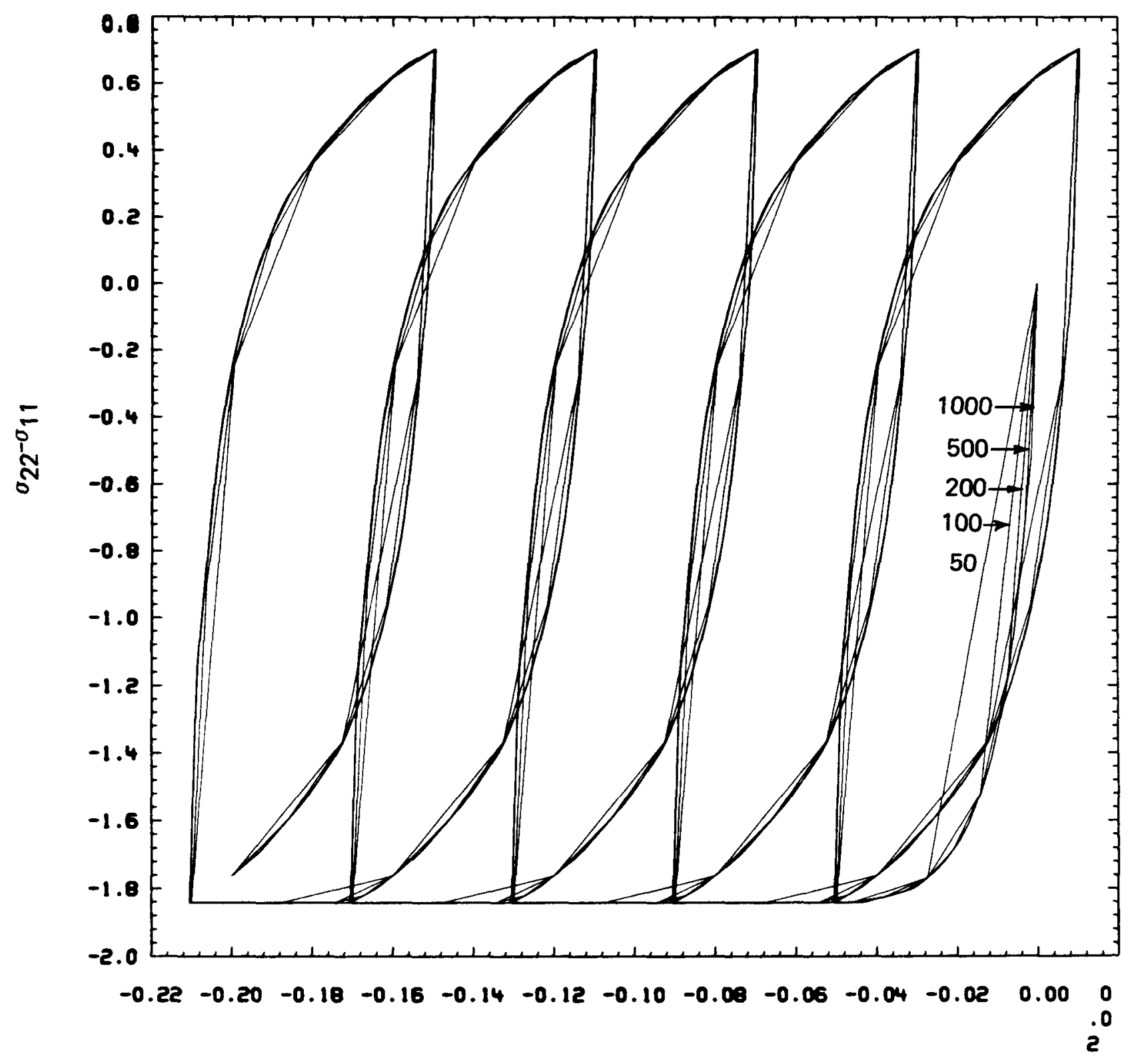

$\epsilon_{22}$

FIG. 13. Drammen clay, triaxial, 5 cycles, $\epsilon_{1}=-.2, \epsilon_{2}=-.04$ 


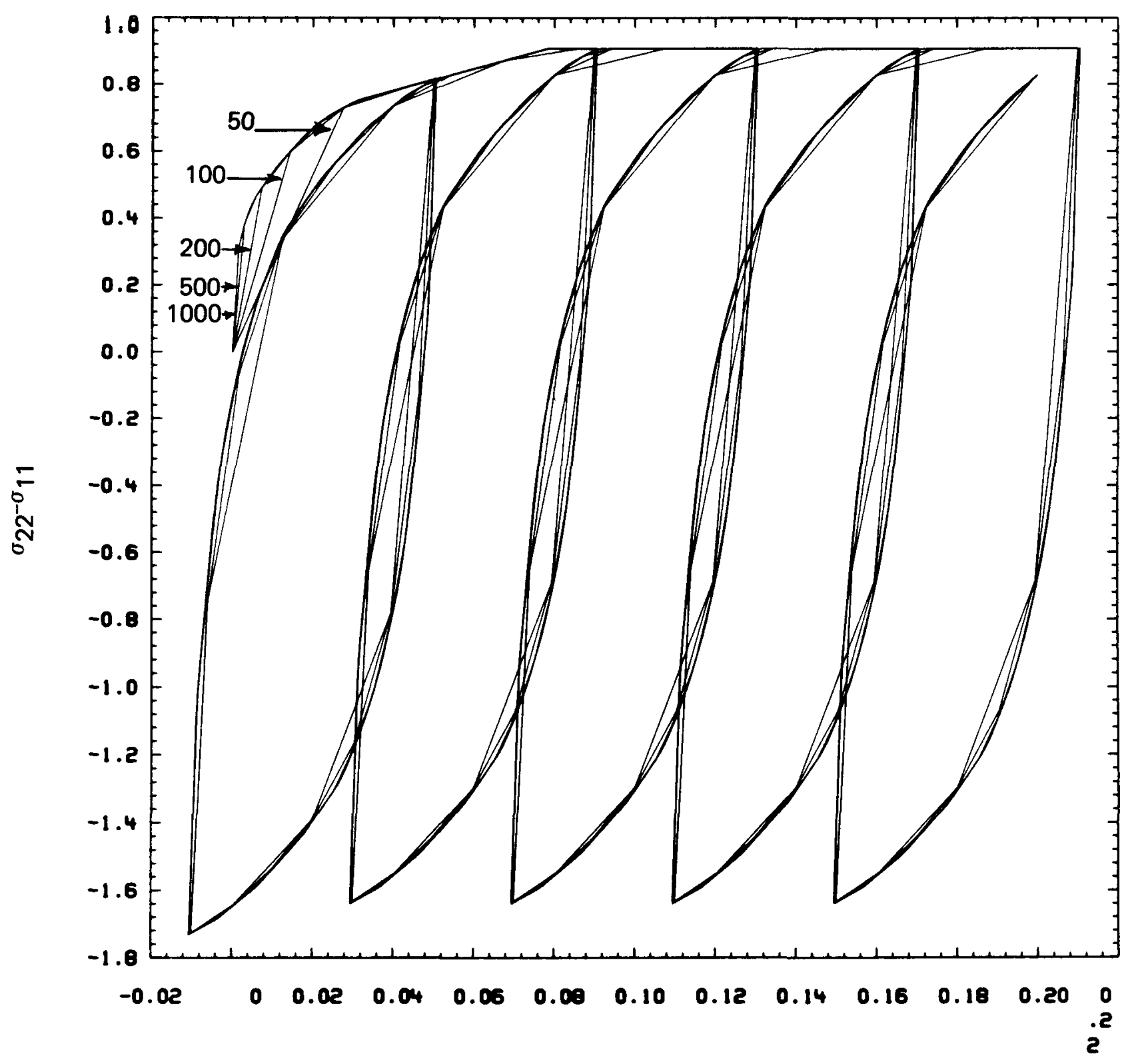

$\epsilon_{22}$

FIG. 14. Drammen clay, triaxial, 5 cycles, $\epsilon_{1}=.2, \epsilon_{2}=.04$ 


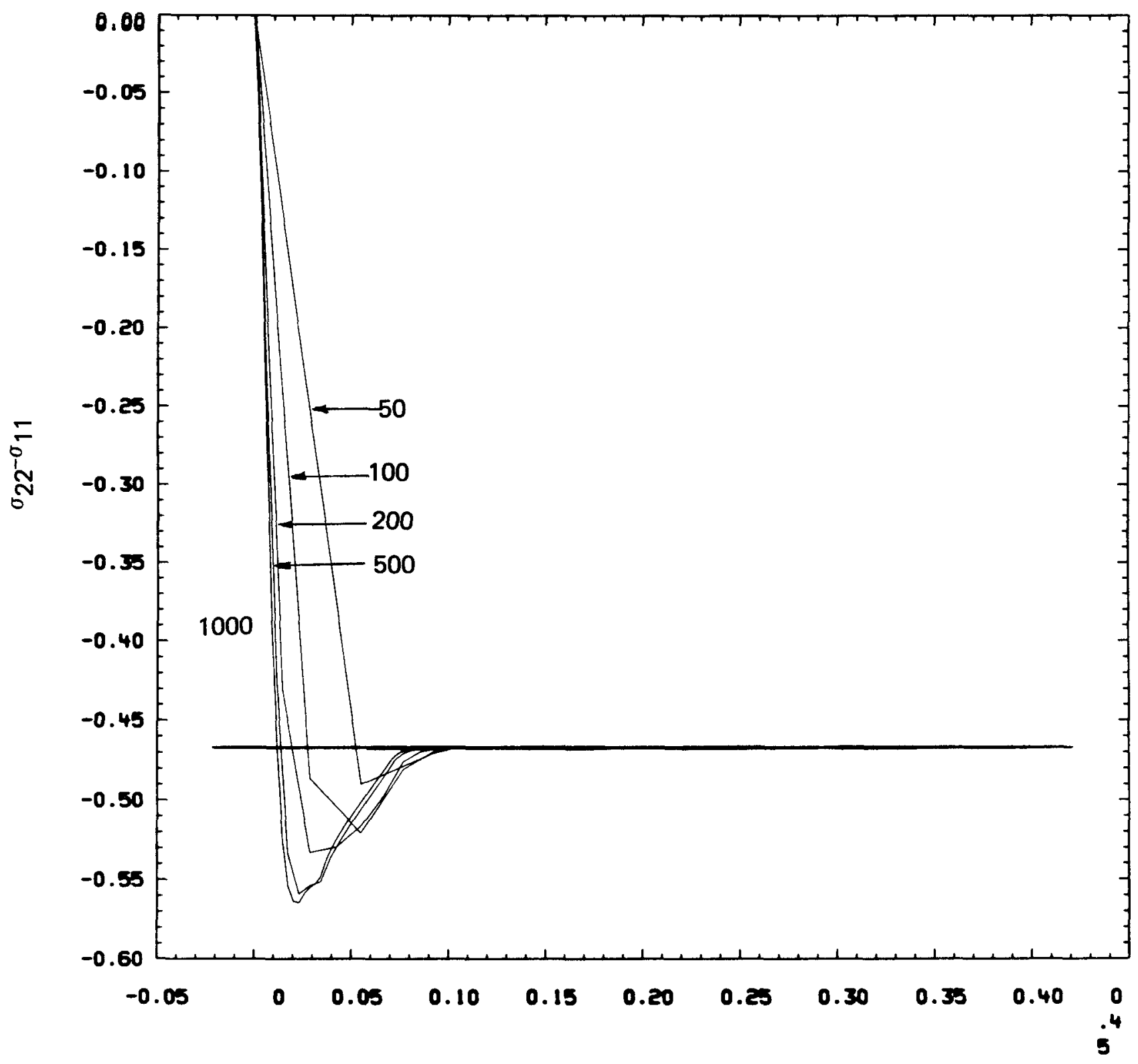

$\gamma$

FIG. 15. Drammen clay, simple shear, 5 cycles, $\epsilon_{1}=.4, \epsilon_{2}=.08$. 


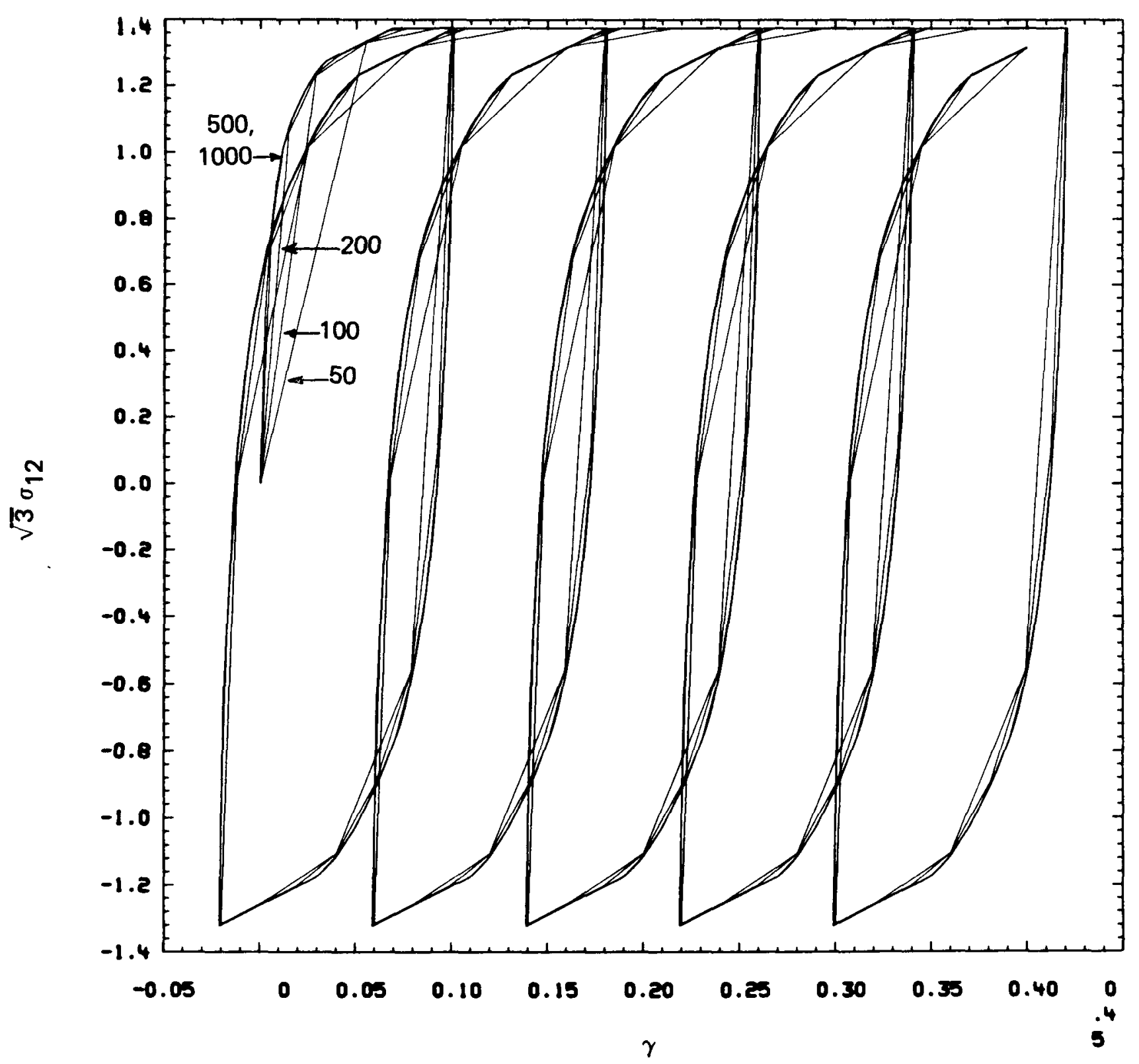

FIG. 16. Drammen clay, simple shear, 5 cycles, $\epsilon_{1}=.4, \epsilon_{2}=.08$. 


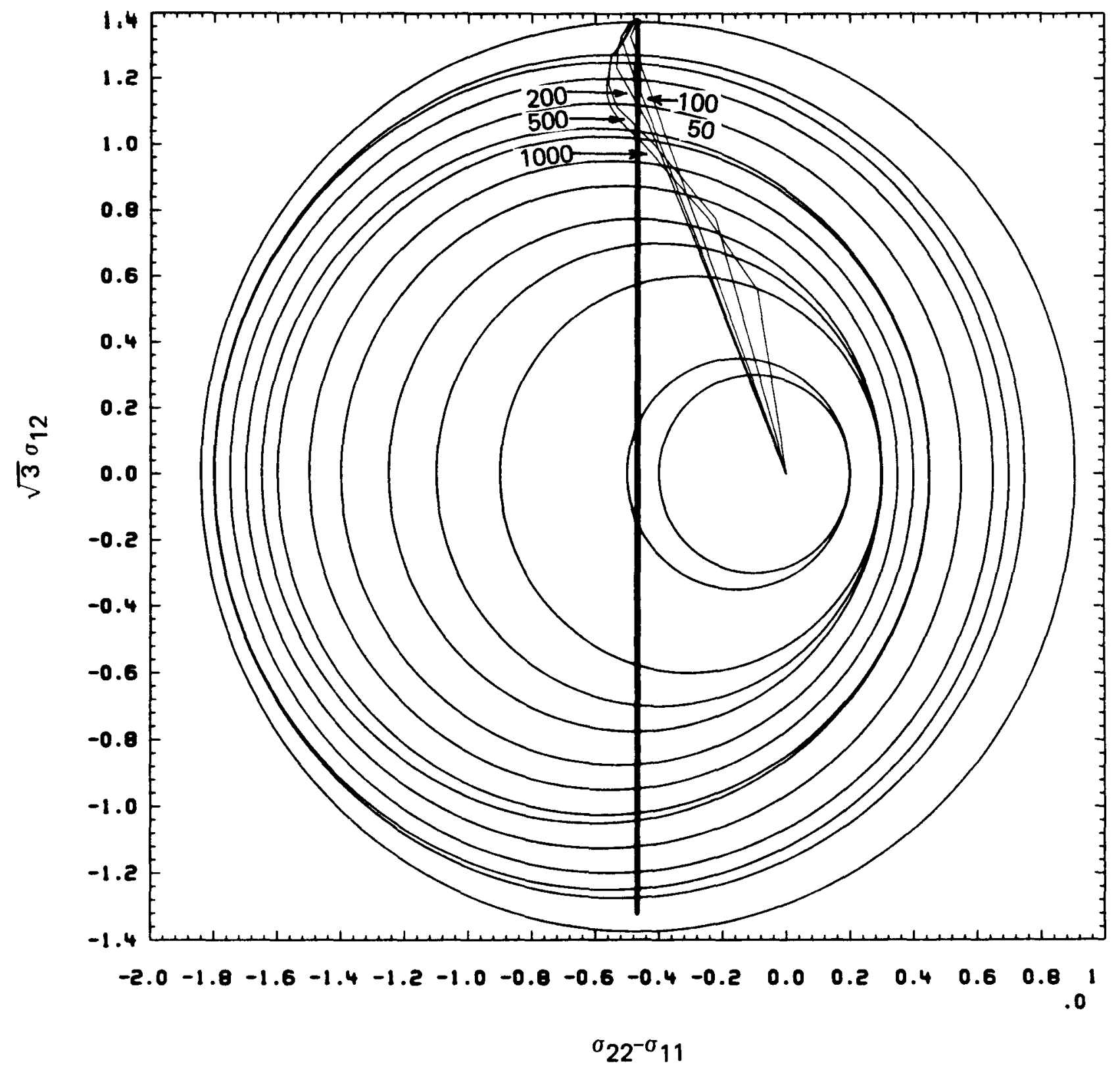

FIG. 17. Drammen clay, simple shear, 5 cycles, $\epsilon_{1}=.4, \epsilon_{2}=.08$. 


\section{b. Dilating sand [14]}

"Dilating sand" is a synthecized soil model which accounts for volumetric plasticity. Data are presented in Table 2. The plastic shear moauli are defined by Eq. (40) and the $\alpha_{i j}$ 's are defined by

$$
\begin{aligned}
& \alpha_{11}=\alpha_{22}=-\alpha_{1} / 3+\alpha_{2} \\
& \alpha_{22}=2 \alpha_{1} / 3+\alpha_{2} \\
& \alpha_{i j}=0 \text { if } i \neq j
\end{aligned}
$$

Cyclic simple shear and constant-volume triaxial tests were run. In constant-volume triaxial tests the nonzero strains are

$$
\begin{aligned}
& \varepsilon_{11}=\varepsilon_{2} \text { sinwt } \\
& \varepsilon_{22}=-2 \varepsilon_{11} \\
& \varepsilon_{33}=\varepsilon_{11}
\end{aligned}
$$

Results are presented in Figs. $18-23$. The results for 320 steps may be viewed as converged. 
Table 2. Dilating sand data

Elastic properties: $G=19,650, \quad B=3,451, \nu=-.4824$ (Poisson's ratio)

Yield surface data: $c=3 / \sqrt{2}=2.12132, \quad \beta=0$ (kinematic hardening)

\begin{tabular}{|rrrrrrr|}
\hline$m$ & $\alpha_{1}$ & $\sqrt{3} k$ & $h$ & $\alpha_{2}$ & $B^{\prime}$ & $A$ \\
\hline 1 & -14.27 & 17.88 & 31,410 & -47.91 & 119,800 & -3.803 \\
2 & -28.11 & 34.59 & 25,380 & -45.83 & 56,090 & -3.972 \\
3 & -36.39 & 47.13 & 19,610 & -46.59 & 27,900 & -2.829 \\
4 & -43.48 & 56.79 & 15,350 & -48.90 & 16,430 & -2.177 \\
5 & -45.27 & 68.62 & 9,848 & -53.32 & 6,962 & -1.664 \\
6 & -52.65 & 80.90 & 5,782 & -59.11 & 3,056 & -1.490 \\
7 & -61.93 & 103.10 & 3,385 & -65.31 & 1,502 & -1.449 \\
8 & -78.75 & 133.50 & 1,332 & -74.60 & 544 & -1.442 \\
9 & -109.36 & 182.70 & 0 & -89.29 & 0 & 0.000 \\
\hline
\end{tabular}




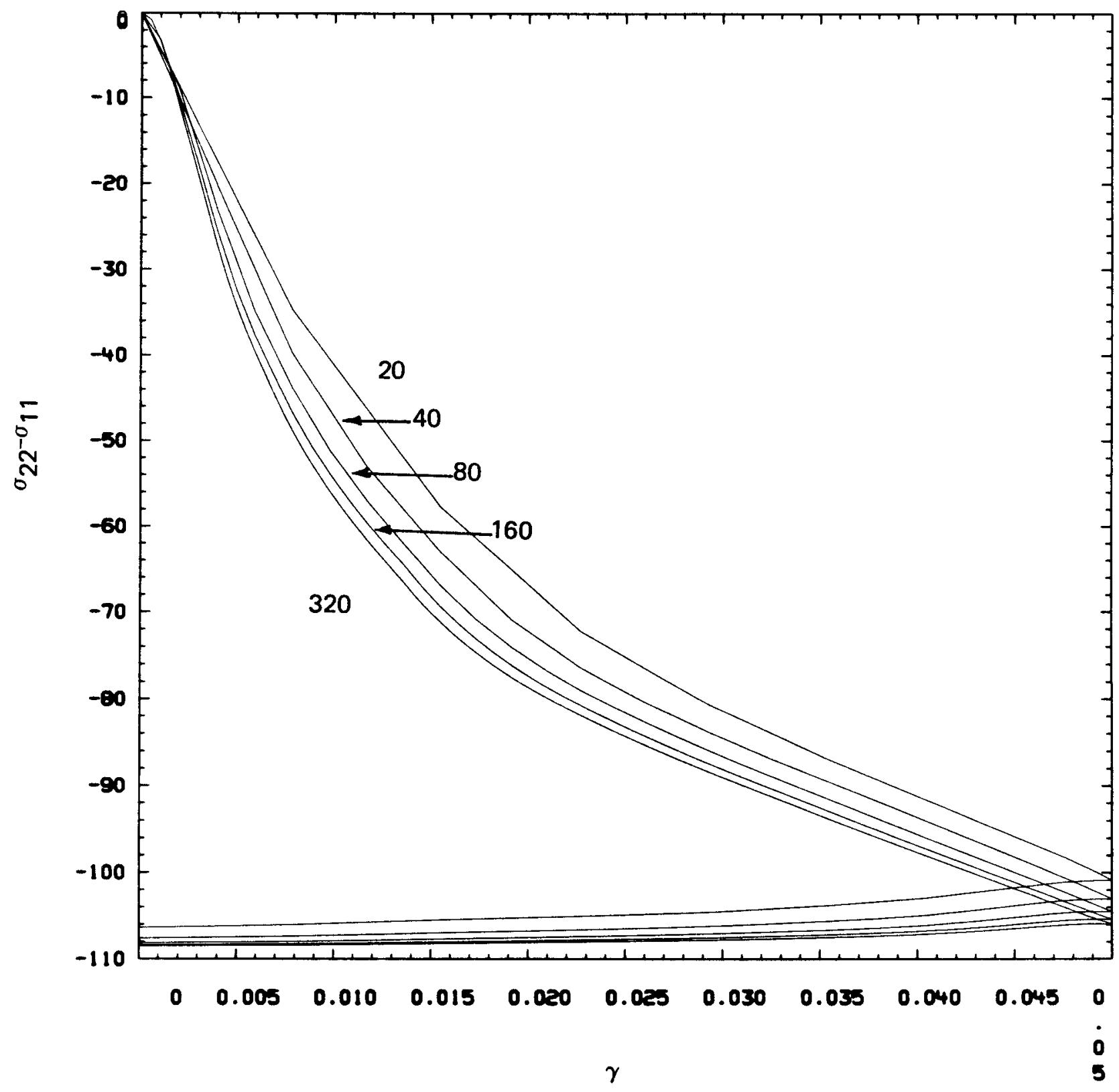

FIG. 18. Dilating sand, simple shear, $1 / 2$ cycle, $\epsilon_{1}=0, \epsilon_{2}=.05$. 


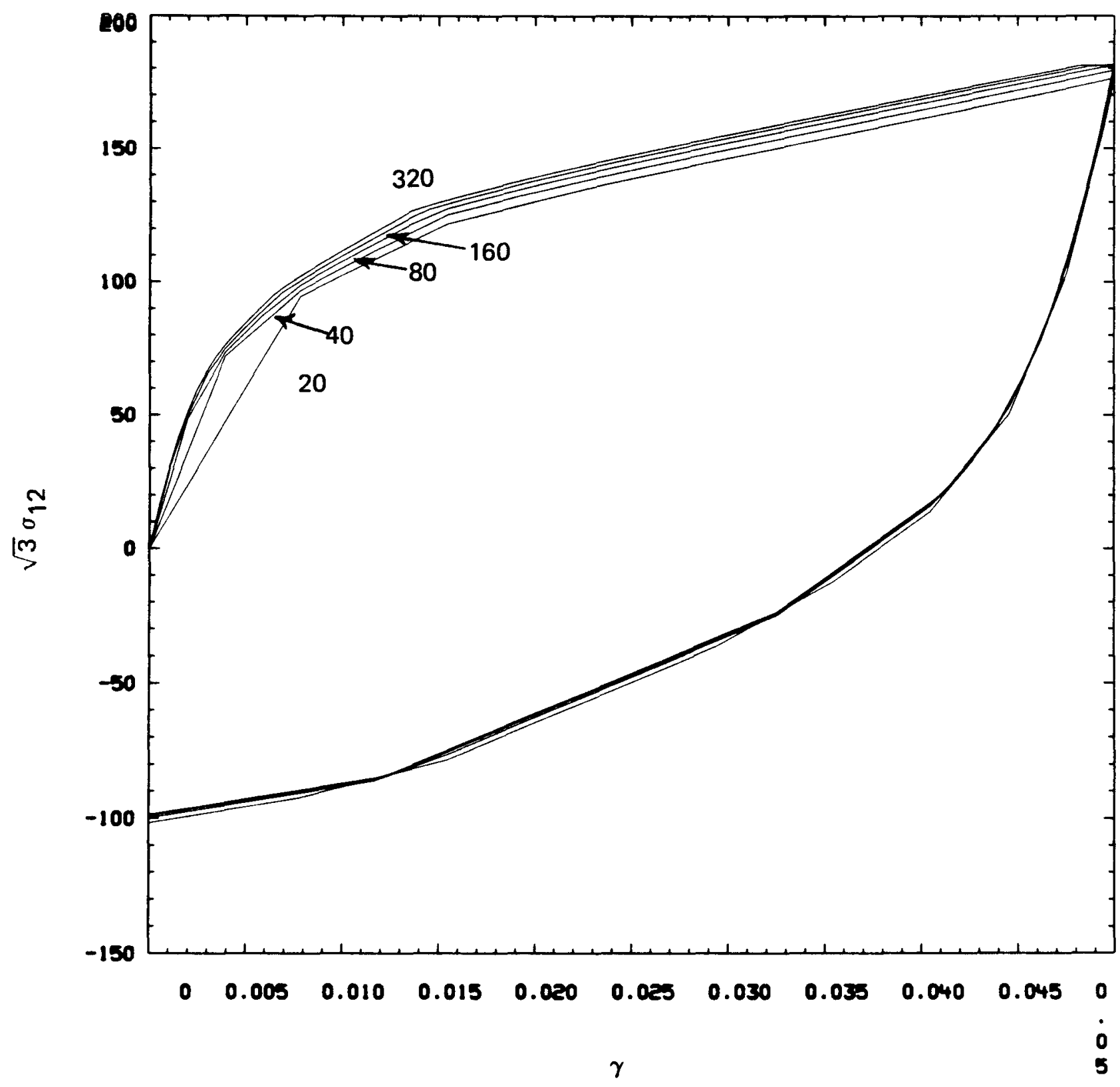

FIG. 19. Dilating sand, simple shear, $1 / 2$ cycle, $\epsilon_{1}=0, \epsilon_{2}=.05$. 


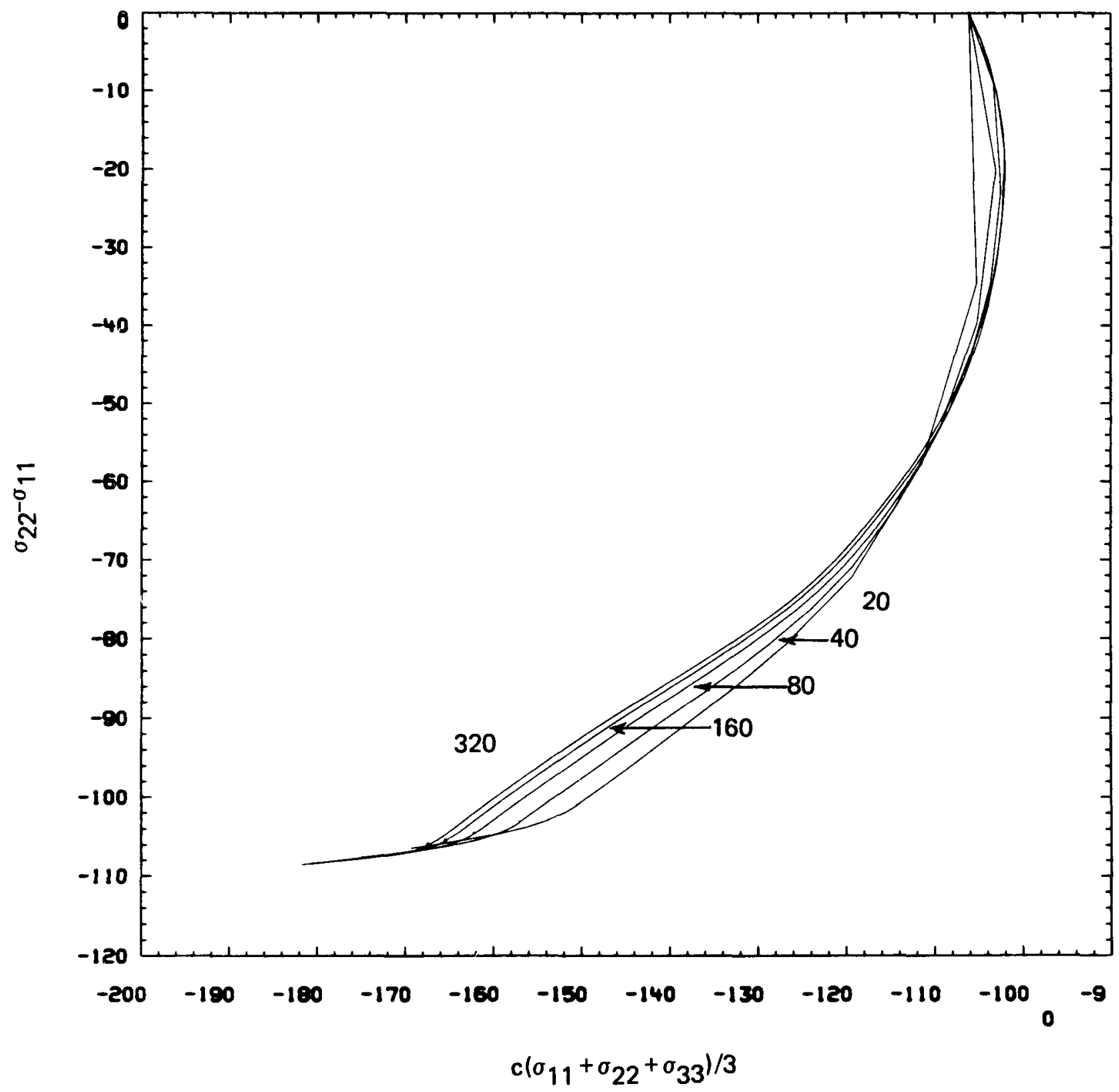

FIG. 20. Dilating sand, simple shear, $1 / 2$ cycle, $\epsilon_{1}=0, \epsilon_{2}=.05$. 


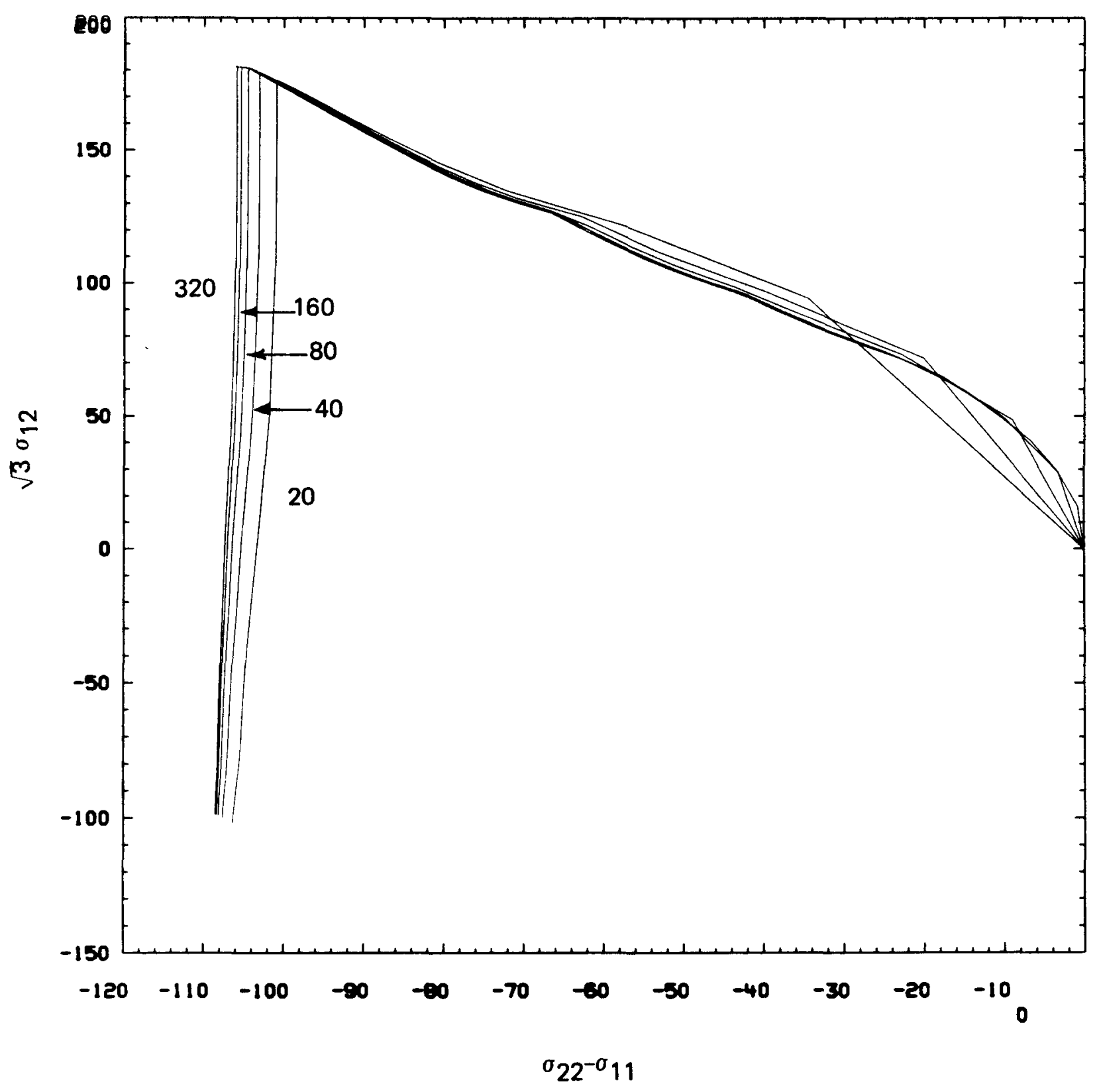

FIG. 21. Dilating sand, simple shear, $1 / 2$ cycle, $\epsilon_{1}=0, \epsilon_{2}=.05$. 


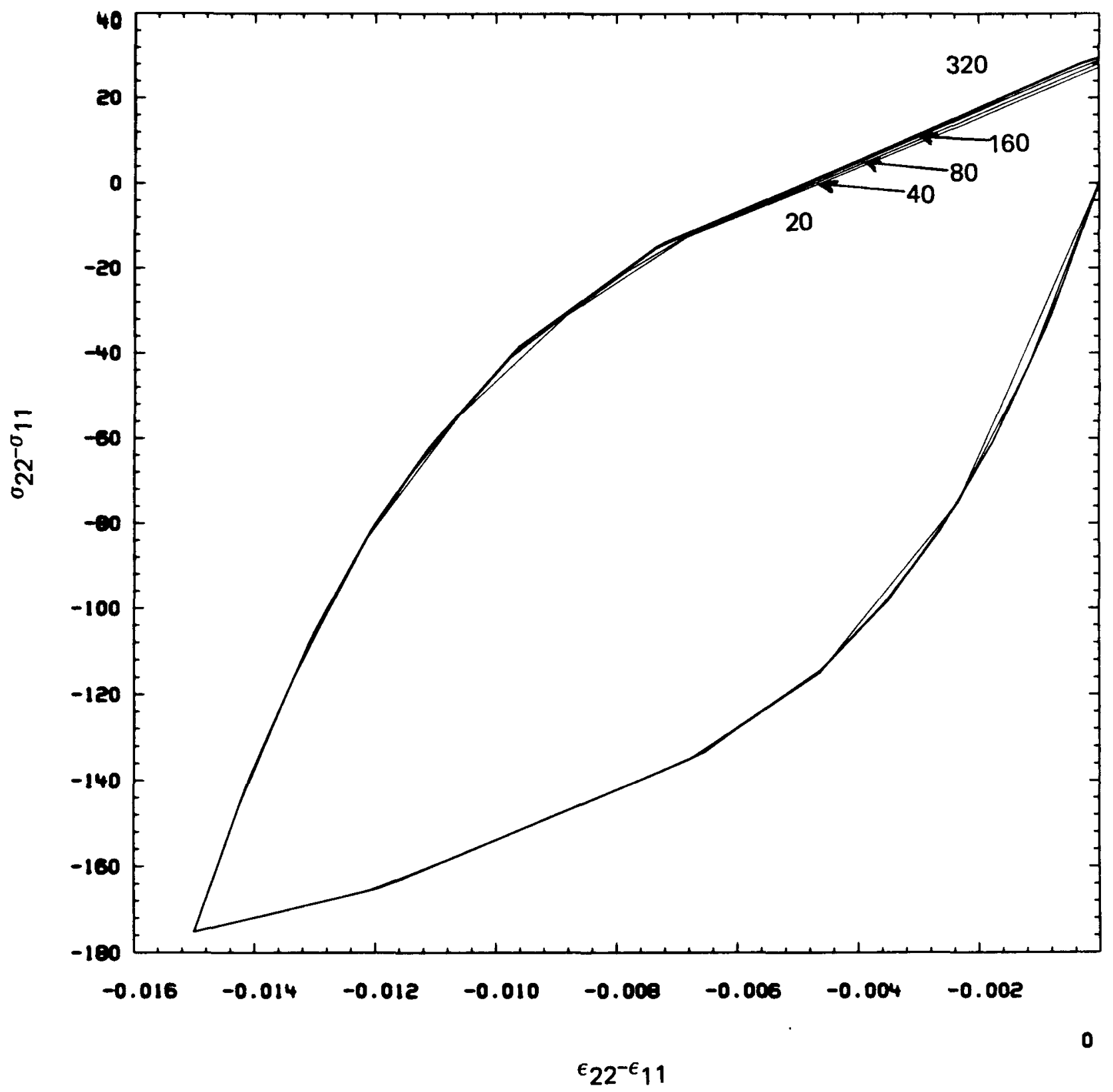

FIG. 22. Dilating sand, constant-volume triaxial, $1 / 2$ cycle, $\epsilon_{1}=0, \epsilon_{2}=.005$. 


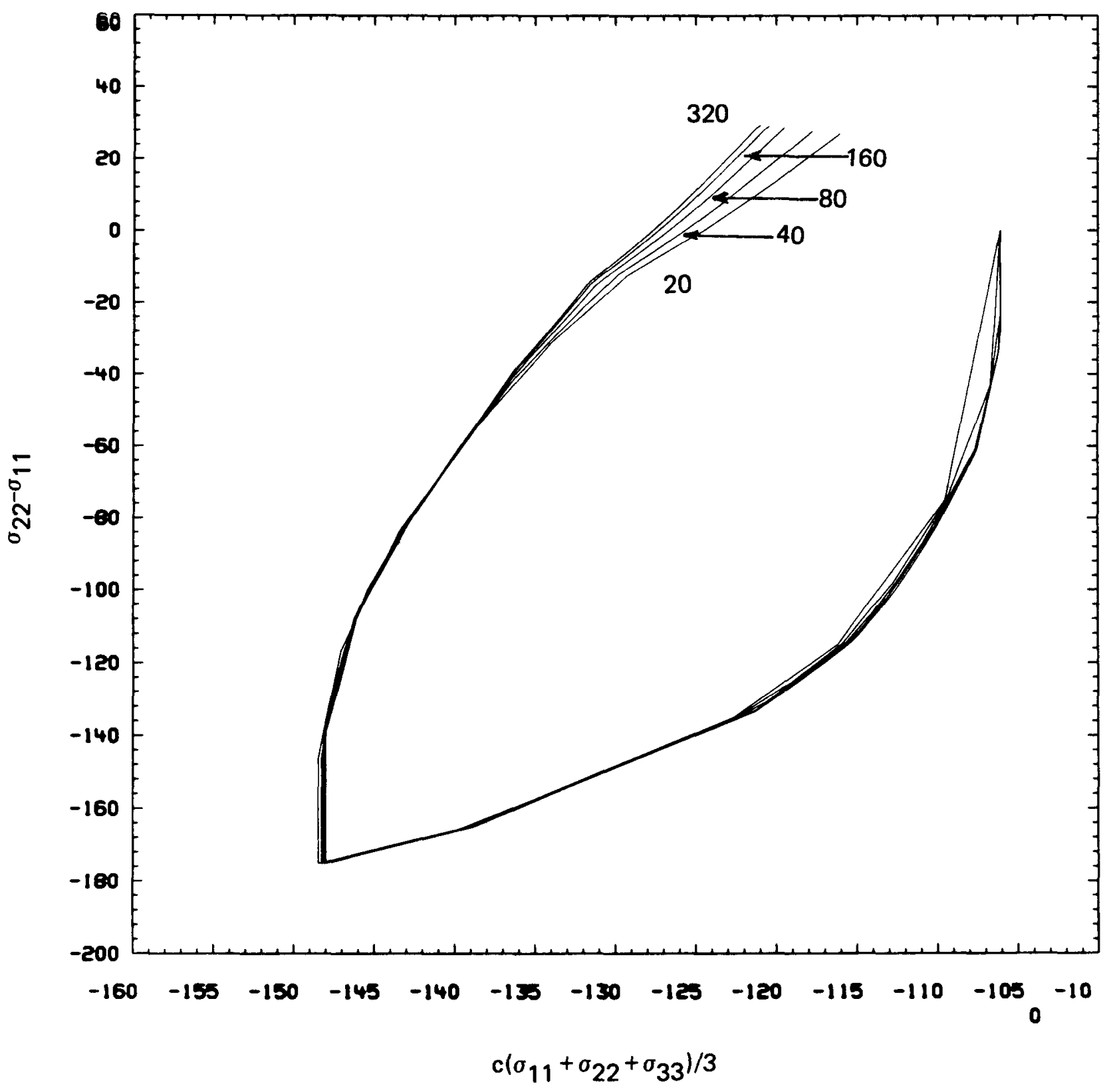

FIG. 23. Dilating sand, constant-volume triaxial, $1 / 2$ cycle, $\epsilon_{1}=0, \epsilon_{2}=.005$. 


\section{CONCLUSIONS}

A pressure-sensitive multiple-yield-surface plasticity theory has been presented which is a variation of a theory developed by Prévost [12]. A linear combination of isotropic and kinematic hardening is accounted for in the manner described by Krieg and Key [5]. A numerical algorithm has been designed which achieves a greater degree of "robustness" than traditional type algorithms, and this opens the way to practical application of the theory to large-scale engineering problems. Constitutive software has been developed to be compatible with large-scale production codes in use at LLNL.

At this point there is still only a paucity of pressure-sensitive experimental data appropriate for evaluating the theory and algorithms. However, a degree of confidence has been attained in the deviatoric-plasticity case. Future work should therefore be focused upon achieving a better understanding of the pressure-sensitive behavior of the theory and its computer implementation. 


\section{REFERENCES}

1. R. C. Chun, et al., "A Comparison of Nonlinear and Equivalent Linear Methods in Soil-Structure Interaction Analysis of a Nuclear Power Plant," University of California, Lawrence Livermore National Laboratory, Rept. UCRL-53031 (1981).

2. R. C. Chun, et al., "Uncertainty in Soil-Structure Interaction Analysis of a Nuclear Power Plant," University of California, Lawrence Livermore National Laboratory, Rept. UCRL-84199, presented to Sixth SMiRT Conference, Paris, France (1981).

3. J. O. Hallquist, "User's Manuals for DYNA3D and DYNAP, (Nonlinear Dynamic Analysis of Solids in Three Dimensions), "University of California, Lawrence Livermore National Laboratory, Rept. UCID-19156 (1981)

4. W. D. Iwan, "On a Class of Models for the Yielding Behavior of Continuous and Composite Systems," Journal of Applied Mechanics, Vol. 34, pp. 612-617 (1967).

5. R. D. Krieg and S. W. Key, "Implementation of a Time Independent Plasticity Theory Into Structural Computer Programs," in Constitutive Equations in Viscoplasticity Theory: Computational and Engineering Aspects, AMD - Vol. 20, ASME, New York (1976).

6. R. D. Krieg and D. B. Krieg, "Accuracies of Numerical Solution Methods for the Elastic-Perfectly Plastic Model," Journal of Pressure Vessel Technology, pp. 510-515, (1977).

7. Z. Mroz, "On the Description of Anisotropic Workhardening," Journal of the Mechanics and Physics of Solids, Vol. 15, pp. 163-175 (1967).

8. Z. Mroz, V. A. Norris and O. C. Zienkiewicz, "An Anisotropic Hardening Model for Soils and its Application to Cyclic Loading," preprint. 
9. J. H. Prévost, "Undrained Stress-Strain Time Behavior of Clays," Journal of the Geotechnical Engineering Division, Vol. 102, pp. 1245-1259 (1976).

10. J. H. Prévost, "Mathematical Modelling of Monotonic and Cyclic Undrained Clay Behavior," International Journal for Numerical and Analytical Methods in Geomechanics, Vol. 1, pp. 195-216 (1977).

11. J. H. Prévost, "Anisotropic Undrained Stress-Strain Behavior of Clays," Journal of the Geotechnical Engineering Division, Vol. 104, pp. 1075-1090 (1978).

12. J. H. Prévost, "Nonlinear Anisotropic Stress-Strain-Strength Behavior of Soils," preprint.

13. J. H. Prévost and T. J. R. Hughes, "Finite Element Solution of Boundary-Value Problems in Soil Mechanics," Proceedings of the International Symposium on Soils Under Cyclic and Transient Loading, Swansea, U. K. (1980).

14. J. H. Prévost, Private communication, 1982. 